\title{
DESIGNAÇÕES PARA RIACHO/CÓRREGO NA REGIÃO NORTE DO BRASIL
}

\section{DESIGNATIONS FOR RIACHO / CÓRREGO IN THE NORTHERN REGION OF BRAZIL}

\author{
Romário Duarte Sanches ${ }^{1}$ \\ Stella Trindade Moreira ${ }^{2}$ \\ Abdelhak Razky ${ }^{3}$
}

Resumo: Este trabalho busca mostrar a variação lexical para o item riacho/córrego nas cidades interioranas da Região Norte do Brasil, além de comparar esses resultados com o estudo feito por Razky e Sanches (2016). Para isso, consultamos o banco de dados do Projeto Atlas Linguístico do Brasil (ALiB). O item lexical analisado corresponde à primeira pergunta do Questionário Semântico-Lexical (QSL). O questionário foi aplicado em 18 cidades da Região Norte e respondido por quatro informantes de cada localidade. Os resultados apontam que a variante igarapé caracteriza o falar do Norte do Brasil nas capitais e nas cidades interioranas.

Palavras-chave: Dialetologia; Geolinguística; Variação lexical; Projeto ALiB.

Abstract: This work aims to show the lexical variation of the item riacho/córrego in the inland cities of the northern region of Brazil, in addition to comparing these results with the data found by Razky and Sanches (2016). For this, the database of the Linguistic Atlas of Brazil Project (ALiB) was consulted. The lexical item analyzed corresponds to the first question of the Semantic-Lexical Questionnaire (QSL). The questionnaire was applied in 18 cities in the northern region and answered by four informants from each locality. The results indicate that the igarapé variant characterizes the northern Brazilian speaking in capitals and inland cities.

Keywords: Dialecology; Geolinguistic; Lexical variation; Project ALiB.

\section{Introdução}

O presente estudo tem como base o banco de dados do projeto Atlas Linguístico do Brasil (ALiB). Este projeto se firmou há mais de 20 anos na Universidade Federal da Bahia (UFBA), sob a presidência da professora Suzana Cardoso, umas das principais referências em

\footnotetext{
${ }^{1}$ Mestrado em Letras (Estudos Linguísticos) pela Universidade Federal do Pará (UFPA). Atualmente é discente do curso de Doutorado em Letras (Estudos Linguísticos) da Universidade Federal do Pará (UFPA) e professor colaborador na Universidade do Estado do Pará (UEPA). E-mail: duarte.romrio@ gmail.com.

${ }^{2}$ Especialização em Estudos Linguística e Análise Literária pela Universidade do Estado do Pará (UEPA). Atualmente é discente do curso de Mestrado em Letras (Estudos Linguísticos) da Universidade Federal do Pará (UFPA). E-mail: stella_trindade@hotmail.com.

${ }^{3}$ Doutorado em Linguística pela Université de Toulouse Le Mirail e pós-doutorado pela Université de Toulouse Le Mirail. Atualmente é professor da Universidade Federal do Pará (UFPA), em exercício no Departamento de Línguas Estrangeiras e Tradução (LET) da Universidade de Brasília (UnB). E-mail: arazky@ gmail.com.
} 
relação aos estudos geolinguísticos atuais no Brasil. O objetivo central do projeto ALiB é descrever e mapear o português falado no Brasil. Em 2014 foi lançado os primeiros volumes do atlas, reunindo mapas fonéticos, lexicais, morfossintáticos e dentre outros domínios do português brasileiro. Além do $\mathrm{ALiB}$, considerado um projeto macro, abrangendo todo o território nacional, é possível ter acesso a outros atlas linguísticos de caráter regional, como Atlas Prévio dos Falares Baianos (ROSSI, et al., 1963); Esboço de um Atlas Linguístico de Minas Gerais (ZÁGARI, et al., 1977); Atlas Linguístico da Paraíba (ARAGÃO; MENEZES, 1984); Atlas Linguístico-Etnográfico da Região Sul (KOCH, et al., 2002; 2011); Atlas Linguístico de Sergipe (FERREIRA, et al., 1987); Atlas Linguístico do Paraná (AGUILERA, 1994); Atlas Linguístico Sonoro do Pará (RAZKY, 2004); Atlas Linguístico do Mato Grosso do Sul (OLIVEIRA, et al., 2007); Atlas Linguístico do Amazonas (CRUZ, 2004); Micro Atlas Fonético do Estado do Rio de Janeiro (ALMEIDA, 2008); Atlas Linguístico de Pernambuco (SÁ, 2013); Atlas Linguístico de Goiás (MILANI; REZENDE; CRUZ; SILVA, 2015); e o Atlas Linguístico do Amapá (RAZKY, RIBEIRO e SANCHES, 2017). Esses atlas linguísticos trazem uma enorme contribuição para a sociedade brasileira, sobretudo, para a linguística nacional que busca conhecer cada vez mais o português do Brasil.

$\mathrm{Na}$ intenção de acrescentar ao projeto ALiB, este estudo busca descrever e mapear as designações para o item lexical riacho/córrego nas cidades interioranas da Região Norte do Brasil. Pretendemos ainda comparar os resultados aqui explorados com os de Razky e Sanches (2016), referentes as capitais brasileiras.

$\mathrm{O}$ artigo está divido em quatro seções. Na primeira, revistamos os conceitos de agrupamentos lexicais e isoglossas. No segundo, abordamos os procedimentos metodológicos adotados para este estudo. No terceiro, apresentamos os resultados da pesquisa. E por último comparamos os resultados desta pesquisa com os resultados já publicados sobre o mesmo item lexical.

\section{Revisitando conceitos: isoglossas e agrupamentos lexicais}

$\mathrm{O}$ advento da modernidade e o uso de tecnologias para a comunicação em sociedade, fez com as pessoas passassem a se comunicar de forma rápida e dinâmica. Esse cenário favoreceu à mobilidade comunicativa dos falantes e consequentemente repercutiu em conceitos basilares do pensamento geolinguístico tradicional, como o conceito de isoglossas, que, grosso modo, podem ser descritas como a linha imaginária que delimita o espaço geográfico de uma dada variedade linguística. 
Com o desenvolvimento da geolinguística moderna, os dialetólogos perceberam que a configuração de áreas dialetais não mais sustentava a ideia de isoglossas. Para Razky (2013), a natureza metodológica dos trabalhos monodimensionais da dialetologia favoreceu a produção de cartas isoléxicas, já que não contemplava no cerne da pesquisa informações sociais sobre os falantes.

Com o surgimento da geolinguística pluridimensional (THUN; RADTKE, 1996), as análises geolinguísticas tornaram-se mais complexas, uma vez que agora é possível relacionar dados extralinguísticos e linguísticos compreendendo o espaço geográfico e de seus falantes. De acordo com Razky (2013), atualmente o conceito de isoglossas é inconsistente, pois a realidade linguística brasileira mostra que uma variedade lexical não pode determinar identidades sociodialetais fixas de uma região, mas, sim, apontar tendências de uso. Sendo mais oportuno, por isso, falarmos de uma concepção de variantes linguísticas menos homogênea, que admita a presença de outras variantes em uma mesma demarcação territorial, denominado por Razky (2013) de agrupamentos:

\begin{abstract}
Assim, o conceito de isolexias passa, pouco a pouco, a ceder espaço a um conceito menos homogêneo, que pode ser chamado de agrupamentos, uma vez que, numa mesma localidade, podem ocorrer outras variações de menor uso, mas atestadas pela pesquisa de campo. O conceito de agrupamento lexical vem acompanhando essa mudança em curso do léxico que, por sua vez, é fruto de uma mobilidade geográfica dos falantes e do acesso ao universo lexical do outro, através dos meios de comunicação. Além disso, o fluxo de interações verbais, fruto de redes de comunicações complexas, vem quebrando o paradigma de isolexias ou, pelo menos, o colocando dentro de um conceito do contínuo linguístico bem conhecido dos estudos sociolinguísticos. (RAZKY, 2013, p. 263)
\end{abstract}

A cerca da ideia de agrupamentos lexicais, Razky e Guedes (2015) mostram, por meio de análises de cartas lexicais do projeto Atlas Geossociolinguístico do Pará (ALiPA), como esse conceito se sustenta, além de apresentarem a existência de macro-agrupamentos e de micro-agrupamentos lexicais a partir das mesorregiões do Estado do Pará. Eles concluem que a dinâmica populacional, isto é, o processo de migração, pode ser um dos fatores principais para explicar os usos lexicais falados nessa região. Haja vista que historicamente o Pará recebeu pessoas oriundas de outras regiões do Brasil, como os Gaúchos que se estabeleceram no sudeste paraense. Essa dinâmica social constrói relações culturais híbridas e consequentemente irá refletir no repertório linguístico dos falantes.

\title{
2 Procedimentos metodológicos
}


Os procedimentos metodológicos empregados neste trabalho baseiam-se nas orientações da geolinguística moderna e nos parâmetros metodológicos do projeto ALiB, uma vez que o corpus utilizado para pesquisa compõe o banco de dados do referido projeto.

Assim, o item lexical investigado (riacho/córrego) corresponde a primeira questão do Questionário Semântico-Lexical (QSL) do ALiB, cujo objetivo consiste em saber como os informantes chamavam para o rio pequeno de uns dois metros de largura. A aplicação deste questionário foi feita na Região Norte do Brasil em 18 cidades interioranas: Oiapoque (AP), São Gabriel da Cachoeira (AM), Tefé, Benjamin Constant (AM), Humaitá (AM), Soure (PA), Óbidos (PA), Almerin (PA), Bragança (PA), Altamira (PA), Marabá (PA), Jacareacanga (PA), Conceição do Araguaia (PA), Itaituba (PA), Cruzeiro do Sul (AC), Guajará Mirin (RO), Pedro Afonso (TO) e Natividade (TO). A figura abaixo mostra a rede pontos da Região Norte do projeto $\mathrm{ALiB}$, indicando as cidades interioranas e suas respectivas capitais.

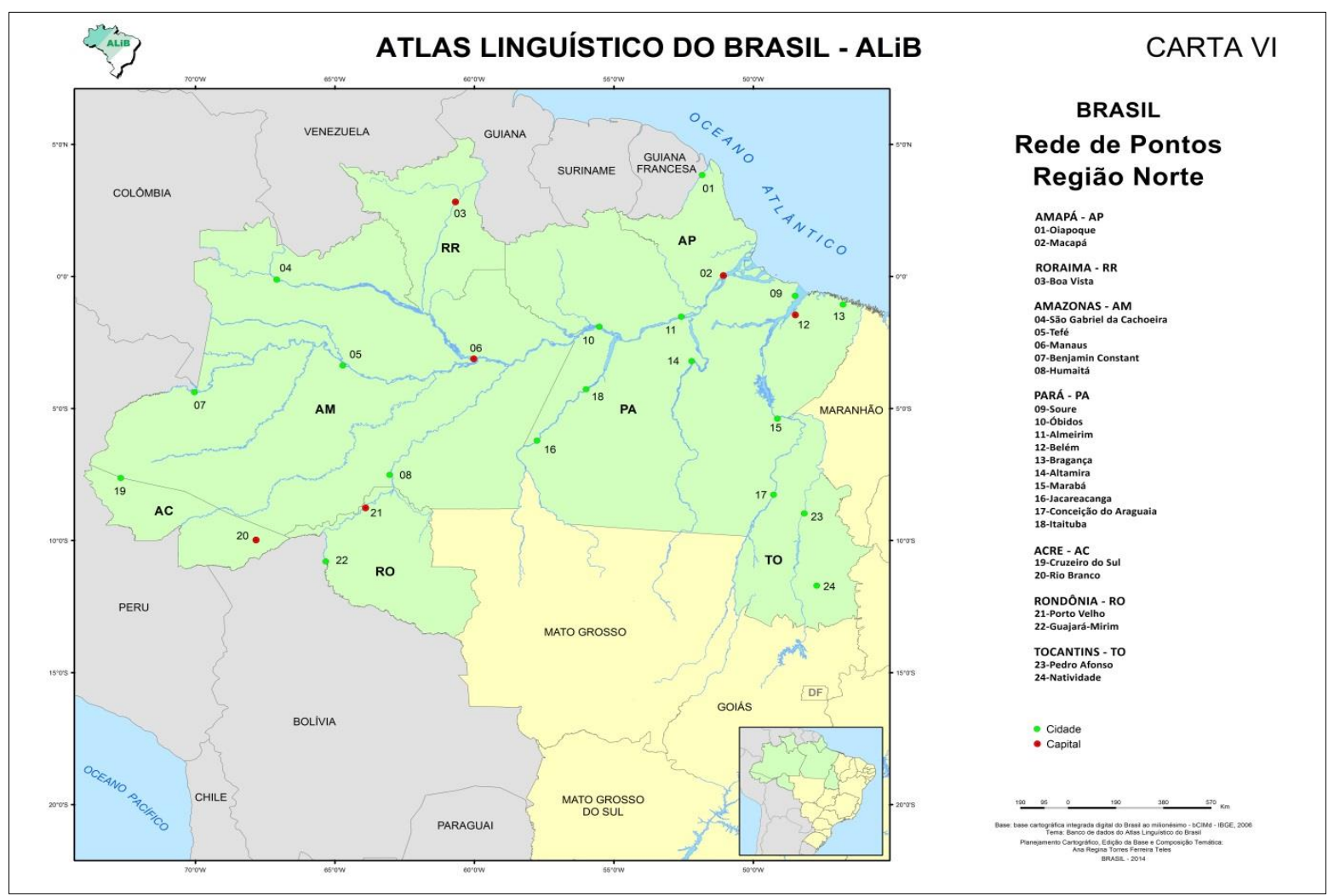

Figura 01: Rede de pontos da Região Norte.

Fonte: Extraído de Cardoso et al. (2014).

Para cada localidade foram selecionados 4 (quatro) informantes com o seguinte perfil: dois homens e duas mulheres, sendo um homem e uma mulher de primeira faixa etária (18-30 
anos) e um homem e uma mulher da segunda faixa etária (50-65 anos). No total foram entrevistados 72 informantes.

As etapas metodológicas para este estudo foi pensada da seguinte forma: 1) organização dos dados em tabelas no programa Excel; 2) validação das respostadas dadas pelos informantes; 3) quantificação e análise dos dados lexicais em valores percentuais; 4) a elaboração da carta lexical diatópica para o referido item estudado; 5) análise dos resultados da variação lexical para riacho/córrego; 6) e como última etapa, comparação dos resultados lexicais encontrados nas cidades interioranas com o trabalho de Razky e Sanches (2016), em que analisam a variação lexical para o mesmo item, porém nas capitais brasileiras.

Antes de adentramos na análise dos resultados foi preciso validar os dados lexicais encontrados, pois algumas respostas dadas pelos informantes não correspondem ao referente perguntado, distanciando-se bruscamente do campo semântico. Isso pode ter sido gerado pela má colocação da pergunta feita pelo inquiridor ou pela incompreensão da pergunta por parte do informante.

Deste modo, registramos nas cidades interioranas do Norte do Brasil 19 (dezenove) respostas para a pergunta 01 do QSL, no entanto, consideramos apenas 10 (dez) como válidas. Essa validação dos dados foi realizada com base nos seguintes critérios: i) frequência da variante lexical; ii) entrada em dicionários; iii) registro em outros atlas regionais; iv) compatibilidade de descrição do referente feita pelos informantes durante a entrevista in loco. Abaixo a tabela 01 mostra as respostas obtidas e as repostas consideradas válidas.

Tabela 01: Designações para lexia riacho/córrego

\begin{tabular}{c|l|l|l}
\hline QSL & \multicolumn{1}{|c|}{ Pergunta } & \multicolumn{1}{c}{ Respostas obtidas } & \multicolumn{1}{c}{ Respostas consideradas válidas } \\
\hline \multirow{01}{*}{$\begin{array}{l}\text { de um rio pequeno, dois metros } \\
\text { de largura? }\end{array}$} & $\begin{array}{l}\text { igarapé, córrego, lago, rio (riozinho), } \\
\text { lagoa, riacho, grota (grotão), ribeirão, } \\
\text { brejo, paraná, braço, gruta, afluente, } \\
\text { praia, balneário, estreito, cachoeira, } \\
\text { represa e rio pequeno }\end{array}$ & $\begin{array}{l}\text { igará, córego, lago, rio (riozinho), } \\
\text { lagoaraná e braço. grota (grotão), ribeirão, }\end{array}$ \\
\hline
\end{tabular}

Fonte: Elaboração dos autores, Belém-PA, 2018.

No caso das respostas como brejo $(0,9 \%)$, gruta $(0,9 \%)$, afluente $(0,9 \%)$, praia $(0,9 \%)$, balneário $(0,9 \%)$, cachoeira $(0,9 \%)$ e represa $(0,9 \%)$ foram invalidadas, pois não houve o cumprimento de quaisquer dos critérios elencados acima: i) as unidades lexicais apresentaram baixa frequência no corpus da pesquisa, cada uma ocorrendo apenas uma vez; ii) ausência de entrada lexical compatível com a designação de um rio pequeno; iii) pouco ou nenhum registro 
nos atlas regionais; iv) e por último, as descrições apresentadas pelos informantes não condiziam com a estrutura conceitual do item lexical.

$\mathrm{O}$ item estreito $(0,9 \%)$, apesar de apresentar ocorrência única, tem entrada dicionarizada, registrada como "sm. 5. Braço de mar que liga dois mares ou duas partes do mesmo mar, canal”; o que pode configurar esta lexia como válida. Entretanto, na nossa avaliação, essa realização foi resultado da tentativa do informante em deduzir a resposta esperada pelo inquiridor ou de desembaraçar-se da questão, produzindo respostas, como "rio pequeno, rio estreito", as quais poderiam ser inferidas por estarem contidas na própria formulação da pergunta feita pelo inquiridor.

Já para as lexias grota/grotão (5\%), rio/riozinho (4\%), ribeirão $(3 \%)$, paraná $(0,9 \%)$ e braço $(0,9 \%)$ foram consideradas válidas, ainda que em alguns casos, como paraná e braço, tenham tido baixa frequência e não foram cartografadas nos atlas consultados. No entanto, a validação dessas lexias consistiu por meio da dicionarização, já que foi possível verificar as entradas lexicais das variantes mencionadas acima com conceitos apropriados para designar um rio pequeno, conforme é demonstrado na tabela a seguir:

Tabela 02: Registro em dicionário

\begin{tabular}{|c|c|}
\hline TERMO/ENTRADA & DEFINIÇÃO \\
\hline braço $s m$. & 1. parte estreita de um rio que penetra terra adentro \\
\hline córrego $\mathrm{sm}$. & 1. sulco aberto pelas águas correntes. 2. ribeiro. \\
\hline grota sf. & 1. abertura produzida pelas enchentes na ribanceira ou na margem de um rio \\
\hline igarapé $s m$. bras. amaz & 1. pequeno rio, às vezes navegável. \\
\hline lago $\mathrm{sm}$. & 1. extensão de água cercada de terra. \\
\hline lagoa $s f$. & 1. lago pouco extenso. \\
\hline paraná $s m$. bras & 1. braço de um rio, separado deste por uma ilha. 2. canal que liga dois rios. \\
\hline riacho sm. & 1. ribeiro. \\
\hline ribeirão $s m$ & 1. curso de água menor que um rio e maior que um ribeiro. \\
\hline rio $s m$. & $\begin{array}{l}\text { 1. curso de água natural que se desloca de nível mais alto para o mais baixo, } \\
\text { aumentando progressivamente até desaguar no mar num lago ou noutro rio. }\end{array}$ \\
\hline
\end{tabular}

Fonte: Extraído de Ferreira (2001).

Em relação aos itens lexicais grota/grotão, rio/riozinho e ribeirão, por outro lado, apresentaram registros em outros atlas regionais (MONTEIRO, 2011; SÁ, 2013; ALTINO, 2007; CRISTIANINI, 2007) e em dicionários, além de serem descritos pelos informantes de maneira compatível ao conceito expresso na pergunta realizada pelo inquiridor, sendo assim consideradas válidas. 
As variantes lexicais igarapé (44\%), córrego (16\%), lago (13\%), riacho (8\%) e lagoa (7\%) também foram consideradas válidas, pois obedecem a todos os critérios de validação: ocorrem com maior frequência no corpus investigado; foram dicionarizadas com propriedades semânticas que correspondem a um rio pequeno; ocorrem em atlas regionais; e foram descritas pelos informantes de forma coerente, correspondendo ao conceito expresso na pergunta 001 do QSL.

\section{Designações para riacho/córrego na Região Norte do Brasil}

As designações ${ }^{4}$ encontradas para riacho/córrego na Região Norte do Brasil foram: igarapé (44\%), córrego (16\%), lago (13\%), lagoa (7\%), riacho (8\%), grotalgrotão (5\%), rio/riozinho (4\%), ribeirão (3\%), paraná $(0,9 \%)$ e braço $(0,9 \%)$. Para apresentação diatópica das variantes lexicais supracitadas elaboramos a carta lexical L01a.

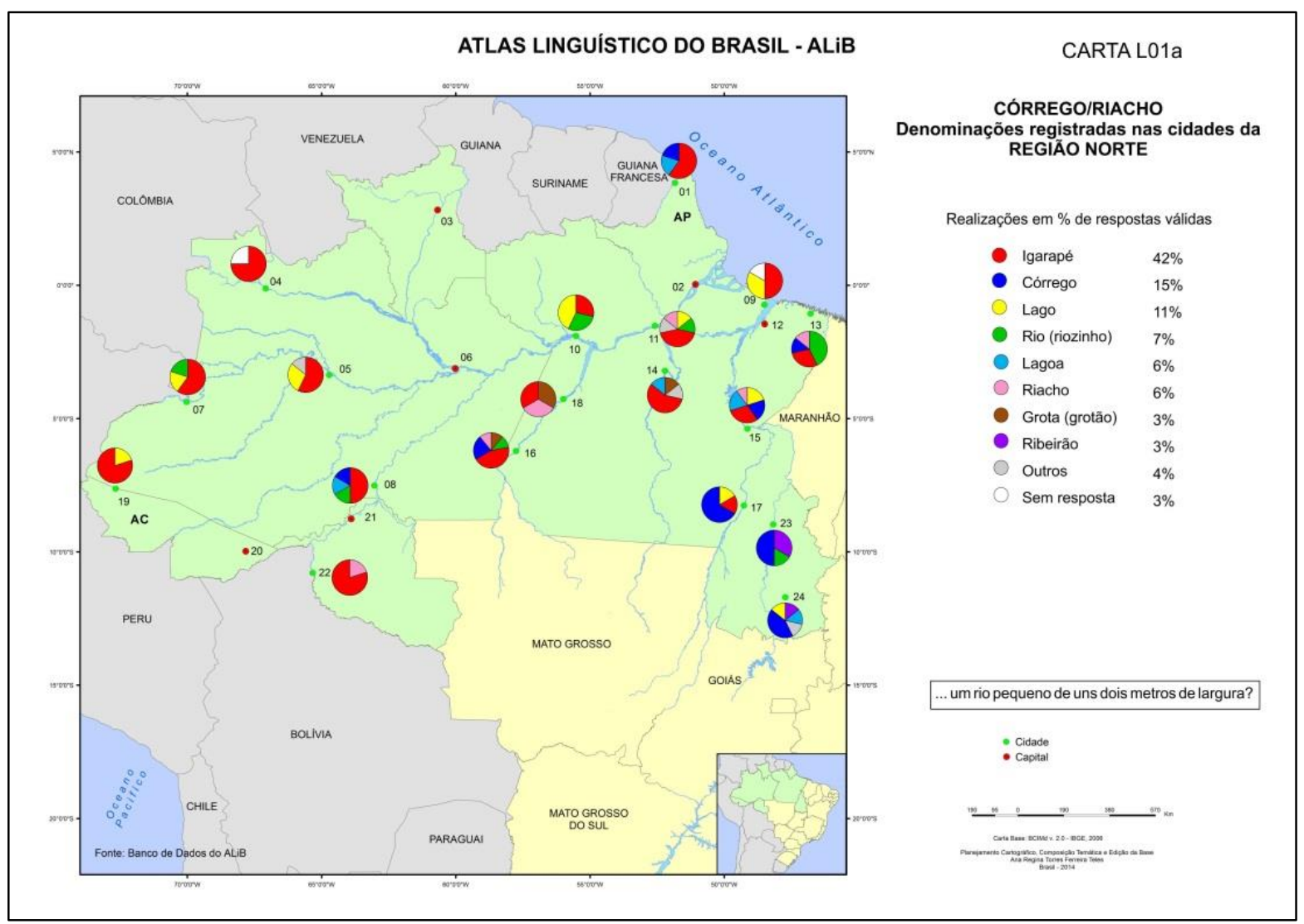

Figura 02: Carta diatópica para riacho/córrego Fonte: Elaboração dos autores, Belém-PA, 2018.

\footnotetext{
${ }^{4}$ Considerando apenas as respostas válidas citadas na seção anterior.
} 
A figura 02 mostra que na Região Norte do Brasil, nas cidades interioranas, a variante lexical mais mencionada pelos informantes foi igarapé, seguida de córrego, lago, rio/riozinho, lagoa e riacho. Já as variantes menos frequentens, isto é, igual ou abaixo de 5\%, foram: grota (grotão), rio (riozinho), ribeirão, paraná, braço.

Diante da perspectiva da geossociolinguística (RAZKY, 2010), as análises apresentadas a seguir têm como foco mostrar a variação geográfica e social do item lexical riacho/córrego. E posteriormente, comparar esses dados com os resultados encontrados no estudo Variação Geossocial do Item Lexical Riacho/córrego nas Capitais Brasileira, de Razky e Sanches (2016).

\section{1 Análise diatópica}

A análise diatópica proposta nesta seção mostra primeiramente uma visão geral da variação geográfica, para em seguida apresentar uma análise local das variantes de riacho/córrego. A tabela 02 aponta o número de ocorrência e de percentagem das variantes lexicais conforme as localidades pesquisadas.

Tabela 02: Distribuição diatópica da variação do item riacho/córrego

\begin{tabular}{|c|c|c|c|c|c|c|c|c|c|c|c|c|c|}
\hline \multicolumn{2}{|c|}{ Localidades } & \multicolumn{2}{|c|}{ igarapé } & \multicolumn{2}{|c|}{ córrego } & \multicolumn{2}{|c|}{ lago } & \multicolumn{2}{|c|}{ lagoa } & \multicolumn{2}{|c|}{ riacho } & \multicolumn{2}{|c|}{ outras } \\
\hline & & ocor. & $\%$ & ocor. & $\%$ & ocor. & $\%$ & ocor. & $\%$ & ocor. & $\%$ & ocor. & $\%$ \\
\hline Amapá & Oiapoque & 03 & $60 \%$ & 01 & $20 \%$ & - & - & 01 & $20 \%$ & - & - & - & - \\
\hline \multirow[t]{4}{*}{ Amazonas } & $\begin{array}{l}\text { São Gabriel da } \\
\text { Cachoeira }\end{array}$ & 03 & $100 \%$ & - & - & - & - & - & & - & - & - & - \\
\hline & Tefé & 04 & $57 \%$ & - & - & 02 & $29 \%$ & - & & - & - & 01 & $14 \%$ \\
\hline & Benjamin Constant & 03 & $50 \%$ & - & - & 01 & $17 \%$ & - & & - & - & 02 & $33 \%$ \\
\hline & humaitá & 03 & $43 \%$ & 01 & $14 \%$ & - & - & 01 & $14 \%$ & - & - & - & - \\
\hline \multirow[t]{9}{*}{ Pará } & Soure & 03 & $60 \%$ & - & - & 02 & $40 \%$ & - & & - & - & - & - \\
\hline & Óbidos & 02 & $29 \%$ & - & - & 03 & $43 \%$ & - & & 02 & $29 \%$ & - & - \\
\hline & Almeirin & 03 & $43 \%$ & - & - & 01 & $14 \%$ & 01 & $14 \%$ & 01 & $14 \%$ & 01 & $14 \%$ \\
\hline & Bragança & 02 & $40 \%$ & 01 & $20 \%$ & - & - & - & & 01 & $20 \%$ & 01 & $20 \%$ \\
\hline & Altamira & 04 & $57 \%$ & - & - & - & - & 01 & $14 \%$ & - & - & 02 & $29 \%$ \\
\hline & Marabá & 03 & $27 \%$ & 02 & $18 \%$ & 02 & $18 \%$ & 03 & $27 \%$ & 01 & $9 \%$ & - & - \\
\hline & Jacareacanga & 04 & $44 \%$ & 02 & $22 \%$ & - & - & - & & 01 & $11 \%$ & 02 & $22 \%$ \\
\hline & $\begin{array}{l}\text { Conceição do } \\
\text { Araguaia }\end{array}$ & 01 & $17 \%$ & 04 & $67 \%$ & 01 & $17 \%$ & - & & - & - & - & - \\
\hline & Itaituba & 02 & $33 \%$ & - & - & - & - & - & & 02 & $33 \%$ & 02 & $50 \%$ \\
\hline Acre & Cruzeiro do Sul & 04 & $80 \%$ & - & - & 01 & $20 \%$ & - & & - & - & - & - \\
\hline Rondônia & Guajará Mirin & 04 & $80 \%$ & - & - & - & & - & & 01 & $20 \%$ & 01 & $0,9 \%$ \\
\hline \multirow[t]{2}{*}{ Tocantins } & Pedro Afonso & - & - & 03 & $60 \%$ & - & - & - & & - & - & 02 & $40 \%$ \\
\hline & Natividade & - & - & 03 & $38 \%$ & 01 & $13 \%$ & 01 & $13 \%$ & - & - & - & - \\
\hline \multicolumn{2}{|c|}{ Total de ocorrências } & 48 & $44 \%$ & 17 & $16 \%$ & 14 & $13 \%$ & 08 & $7 \%$ & 09 & $8 \%$ & 14 & $14 \%$ \\
\hline
\end{tabular}

Fonte: Elaboração dos autores, Belém-PA, 2018. 
Observamos na tabela 02 que a variante de maior frequência nas cidades do interior da Região Norte do Brasil foi igarapé com 48 (44\%) ocorrências, sendo mencionada em quase todas as localidades pesquisadas, exceto Pedro Afonso e Natividade, cidade do Estado de Tocantins.

Vale ressaltar que o mapeamento lexical apresentado acima enfraquece a noção de isoglossas e principalmente de cartas isoléxicas, pois na distribuição varietal da Região Norte foi possível identificar a presença de outras variantes coocorrendo e concorrendo com a variante igarapé, sendo possível, falar em agrupamentos lexicais para o item riacho/córrego.

A variante córrego ocorreu com 16\% de frequência, ocupando o segundo lugar nas escolhas lexicais dos informantes. Porém, esta variante não caracteriza de forma expressiva o falar da Região Norte como um todo, uma vez que sua ocorrência foi nula em muitas localidades (cf. tabela 02). Assim, do total de 18 (dezoito) cidades, córrego apareceu em apenas 7 (sete) com pouca frequência.

A denominação lago, por sua vez, presente em 9 (nove) localidades, representa a terceira variante mais recorrente, com $13 \%$ de incidência, seguida de riacho (8\%) e lagoa $(7 \%)$.

A variante igarapé, como já referido, mostrou-se estável em quase toda a Região Norte do Brasil. Essa configuração vai mudando nas localidades de Conceição do Araguaia, Pedro Afonso e Natividade, onde a ocorrência de igarapé foi nula e a preferência pela designação córrego assumiu a primeira posição, com $50 \%$ de frequência em Pedro Afonso, $38 \%$ em Natividade (cidades do Estado de Tocantins) e em Conceição do Araguaia com 58\%. Com isso é possível depreender que córrego pode ser uma variante local do Estado do Tocantins e da cidade de Conceição do Araguaia (PA), podendo ser explicado pela localização fronteiriça ${ }^{5}$ entre essas cidades e pela forte influência migratória de pessoas oriundas de outras regiões do Brasil.

\subsection{Análise da variação diassexual e diageracional}

Nesta seção analisamos as variantes lexicais conforme os fatores sexo e idade, na intenção de identificar se houve influência de fatores extralinguísticos nas escolhas lexicais dos falantes. Para isso, selecionamos as variantes mais frequentes (igarapé, córrego, lago, lagoa e riacho) e agrupamos as menos frequentes em outras, como mostra a tabela 04.

\footnotetext{
${ }^{5}$ A cidade de Conceição do Araguaia (PA) fica localizada na divisa entre os estados do Pará e Tocantins, cerca de $190 \mathrm{~km}$ da cidade de Pedro Afonso (TO).
} 
Tabela 04: Distribuição da variável social sexo

\begin{tabular}{l|c|c|c|c}
\hline \multirow{2}{*}{ VARIANTES } & \multicolumn{4}{|c}{ SEXO } \\
\cline { 2 - 5 } & \multicolumn{3}{|c}{ Masculino } & \multicolumn{2}{c}{ Feminino } \\
\cline { 2 - 5 } & ocor. & $\%$ & ocor. & $\%$ \\
\hline igarapé & 28 & $58 \%$ & 20 & $42 \%$ \\
\hline córrego & 12 & $71 \%$ & 5 & $29 \%$ \\
\hline lago & 6 & $43 \%$ & 8 & $57 \%$ \\
\hline lagoa & 2 & $25 \%$ & 6 & $75 \%$ \\
\hline riacho & 6 & $67 \%$ & 3 & $33 \%$ \\
\hline outras & 8 & $57 \%$ & 6 & $43 \%$ \\
\hline
\end{tabular}

Fonte: Elaboração dos autores, Belém-PA, 2018.

Conforme a tabela 04, a dimensão diassexual apresentou em alguns casos percentagens estáveis, pois ambos os sexos tiveram o número de ocorrência equilibrado. Como no caso da variante igarapé e lago, a primeira ocorreu na fala de homens com 58\% e $42 \%$ na fala de mulheres, a segunda obteve $43 \%$ na fala de homens e $57 \%$ na fala de mulheres. Já as variantes córrego, lagoa e riacho apresentaram influências da variável sexo, uma vez que córrego (71\%) e riacho $(67 \%)$ se destacaram na fala de homens e lagoa $(75 \%)$ na fala de mulheres.

Em relação à dimensão diageracional, apresentamos abaixo a tabela 05 que mostra a distribuição das variantes lexicais de acordo com a faixa etária dos informantes. Dividimos em dois grupos: grupo A que corresponde aos informantes de 18-30 anos e grupo B que corresponde aos informantes de 50-65 anos.

Tabela 05: Distribuição da variável diageracional

\begin{tabular}{l|c|c|c|c}
\hline \multirow{2}{*}{ VARIANTES } & \multicolumn{4}{c}{ FAIXA ETÁRIA } \\
\cline { 2 - 5 } & \multicolumn{2}{|c|}{ A (18-30 anos) } & \multicolumn{2}{c}{ B (50-65 anos) } \\
\cline { 2 - 5 } & ocor. & $\%$ & ocor. & $\%$ \\
\hline igarapé & 20 & $42 \%$ & 28 & $58 \%$ \\
\hline córrego & 7 & $41 \%$ & 10 & $59 \%$ \\
\hline lago & 7 & $50 \%$ & 7 & $50 \%$ \\
\hline lagoa & 8 & $88 \%$ & 1 & $13 \%$ \\
\hline riacho & 2 & $22 \%$ & 7 & $78 \%$ \\
\hline outras & 6 & $43 \%$ & 8 & $57 \%$ \\
\hline
\end{tabular}

Fonte: Elaboração dos autores, Belém-PA, 2018.

Verificamos na tabela 05 os seguintes resultados: nas variantes mais frequentes como igarapé, córrego e lago não houve influência da variável faixa etária, pois a variante igarapé, por exemplo, obteve $42 \%$ de ocorrência na faixa etária A e $58 \%$ na faixa etária B. No caso da 
variante córrego foram registrados $41 \%$ para a faixa etária A e $59 \%$ para a faixa etária $\mathrm{B}$. E para a variante lago a distribuição percentual foi a mesma em ambas as faixas etárias, com 50\% de ocorrência.

Sobre as variantes menos frequentes registradas na Região Norte (lagoa e riacho), a variável diageracional parece exercer influência na seleção lexical dos informantes, chegando a registrar $88 \%$ para lago na fala dos informantes da faixa etária A e $78 \%$ para riacho na fala dos informantes da faixa etária B.

\section{Análise Comparativa}

Para esta análise comparativa, retomamos o estudo realizado por Razky e Sanches (2016) sobre a variação geossocial do item riacho/córrego nas capitais brasileiras, buscando saber em que medida o falar das capitais se distancia ou se aproxima do falar das cidades interioranas da Região Norte do Brasil.

Razky e Sanches (2016) partem de uma observação macro sobre as variantes para riacho/córrego, considerando somente a primeira resposta dos informantes, eles obtiveram os seguintes resultados: no quadro geral das capitais brasileiras, as variantes registradas foram riacho (36\%), córrego (23\%), igarapé (14\%), lago (7\%), lagoa (5\%) e riozinho (5\%). Os autores mostram que riacho foi a variante mais frequente e que pode caracterizar a realidade linguística brasileira para expressar um rio pequeno. Por conseguinte, também foi possível verificar que riacho compõe um agrupamento lexical que abrange a Região Nordeste, Sul e Sudeste; já córrego se destaca na Região Centro-Oeste; e igarapé se concentra na Região Norte.

Essas mesmas variantes lexicais, exceto rio/riozinho foram, também, predominantes nas cidades interioranas da Região Norte. Para facilitar a leitura dos dados comparativos, colocamos lado a lado os resultados percentuais das variantes procedentes das capitais nortistas brasileiras e das cidades interioranas.

Tabela 06: Percentual de frequência nas capitais e não capitais da Região norte

\begin{tabular}{l|c|c}
\hline \multirow{2}{*}{ VARIANTES } & \multicolumn{2}{c}{ Localidades } \\
\cline { 2 - 3 } & cidades capitais & cidades interioranas \\
\hline igarapé & $49 \%$ & $44 \%$ \\
\hline riacho & $13 \%$ & $8 \%$ \\
\hline lago & $11 \%$ & $13 \%$ \\
\hline córrego & $10 \%$ & $16 \%$ \\
\hline lagoa & $1 \%$ & $7 \%$ \\
\hline rio/riozinho & - & $4 \%$ \\
\hline
\end{tabular}

Fonte: Elaboração dos autores, Belém-PA, 2018. 
Observamos na tabela 06 que tanto nas capitais brasileiras quanto nas cidades interioranas igarapé (49\%) é a variante mais frequente e está presente em quase todos os pontos de inquéritos do ALiB, marcando o falar nortista.

Compreendemos, portanto, que o falar das capitais e das cidades interioranas aproximase na medida em que ambas as localidades utilizam as mesmas variantes. No entanto, observamos que o falar dessas localidades afasta-se na medida em que os falantes das capitais manifestam preferência pelo item lexical riacho, que ocupa a segunda posição em frequência de uso, já os falantes das cidades interioranas do Norte optam por córrego como segunda variante de uso disponível.

No caso do uso de riacho como mais frequente nas capitais e assumir a segunda posição nas cidades interioranas, isso pode ser explicado pela configuração do espaço geográfico, demonstrando que nas grandes áreas urbanas há maior fluxo de contato com as redes de comunicação, além de apresentar intensos movimentos populacionais e a forte presença do processo de escolarização. Com isso, o falante pode incorporar em seu repertório linguístico variantes de outras regiões mais midiatizadas ou escolarizadas, posto que Razky e Sanches (2016) atestam que a variante lexical riacho compõe um grande agrupamento lexical que abrange as regiões Nordeste, Sul e Sudeste do Brasil, tratando-a como variante padrão.

\section{Considerações finais}

Os resultados apontam que no Norte do Brasil a variante igarapé (44\%) marca o falar do nortista, pois a maioria dos informantes das capitais e das cidades interioranas da Região Norte usa este termo para nomear um rio pequeno. Os dados também apontam que não foi possível falar em isoglossas e isolexias, pois a ideia de homogeneidade lexical se desfez com a presença de outras variantes, como: córrego, riacho, lago, lagoa, grota, etc.

No tocante à dimensão social (faixa etária e sexo), não houve influência para a variação de igarapé, sendo esta amplamente usada por homens e mulheres de ambas as faixas etárias. Já córrego e riacho, por sua vez, foram usados com maior frequência por homens idosos; e lagoa foi expressiva na fala de mulheres jovens.

Deste modo, o Brasil por possuir dimensões continentais e uma formação social variada, requer trabalhos científicos que forneçam informações precisas para desvelar sua complexa configuração dialetal. Acreditamos ter contribuído para o entendimento da realidade linguística no País, sobretudo, no que diz respeito à variação lexical para riacho/córrego na Região Norte. 


\section{Referências}

AGUILERA,Vanderci de Andrade. Atlas Linguístico do Paraná. Curitiba: Imprensa Oficial do Paraná, 1996.

ALMEIDA, Fabiana da Silva Campos. Micro Atlas Fonético do Estado do Rio de Janeiro (Micro AFERJ): uma contribuição para o conhecimento dos falares fluminenses. Tese (Doutorado em Letras Vernáculas) - Faculdade de Letras da Universidade Federal do Rio de Janeiro, Rio de Janeiro, 2008.

ALTINO, Fabiane. Atlas Linguístico do Paraná (ALPR II). Tese (Doutorado em Estudos da Linguagem) - Universidade Estadual de Londrina. Londrina, 2007.

ARAGÃO, Maria do Socorro Silva de; MENEZES, Cleuza Bezerra de. Atlas Linguístico da Paraíba. Brasília: CNPq, Universidade Federal da Paraíba, 1984.

CARDOSO, Suzana et al. Atlas Linguístico do Brasil. Introdução. Londrina: EDUEL, 2014. v. 1.

Atlas Linguístico do Brasil. Londrina: EDUEL, 2014. v. 2.

CRISTIANINI, Adriana. Atlas Semântico-Lexical da Região do Grande ABC. Tese (Doutorado em Linguística). São Paulo, 2007.

CRUZ, Maria Luiza de Carvalho. Atlas Lingüístico do Amazonas. Tese (Doutorado em Letras) - Universidade Federal do Rio de Janeiro, Rio de Janeiro, 2004. v. I e II.

FERREIRA, Aurélio. Dicionário da Língua Portuguesa. Rio de Janeiro: Nova Fronteira, 2001.

FERREIRA, Carlota et al. Atlas Lingüístico de Sergipe (ALS). Salvador: UFBA-FUNDESC, 1987.

MILANI; Sebastião Elias; REZENDE, Tânia Ferreira; CRUZ, Aline da; SILVA, Daniel Marra da. Atlas Linguístico de Goiás (ALINGO): léxico-fonético. Rio de Janeiro: Barra Livros, 2015.

MONTEIRO, Jamyli. Atlas Linguístico Léxico-semântico de Capistrano. Dissertação (Mestrado Acadêmico em Linguística Aplicada) - Universidade Estadual do Ceará. Fortaleza, 2011.

OLIVEIRA, Decir Pedro de (org.). Atlas Linguístico do Mato Grosso do Sul. 1. ed. Campo Grande: Editora UFMS, 2007.

RAZKY, Abdelhak; GUEDES, Regis. Le continuum des regroupements lexicaux dans l'atlas géosociolinguistique du Pará. Revista Géoliguistique. n. 15-2015. Centre de Dialectologie. GIPSA-lab - Univ. Grenoble Alpes, 2015.

RAZKY, Abdelhak; RIBEIRO, Celeste; SANCHES, Romário. Atlas Linguístico do Amapá. São Paulo: Labrador, 2017. 
RAZKY, Abdelhak; SANCHES, Romário. Variação geossocial do item lexical riacho/córrego nas capitais brasileiras. Gragoatá, Niterói, n.40, p. 70-89, 1.sem. 2016.

RAZKY, Abelhak. A dimensão sociodialetal do léxico no Projeto Atlas Linguístico do Brasil. Signum: estudos linguísticos, Londrina, n. 16/2, p. 247-270, dez. 2013.

Rom]. (org.) Atlas linguístico sonoro do Pará. Belém: UFPA; CAPES; UTM, 2004. [1CD-

. Pour une approche géo-sociolinguistique de la variation phonétique. Lenguaje (Universidad del Valle), v. 32, 2010, p. 313-330.

ROSSI, Nelson; FERREIRA, Carlota; ISENSEE, Dinah. Atlas Prévio dos Falares Baianos. Rio de Janeiro: Ministério de Educação e Cultura; Instituto Nacional do Livro, 1963.

SÁ, Edmilson. Atlas Linguístico de Pernambuco (ALiPE). Tese (Doutorado em Letras) Universidade Federal da Paraíba. João Pessoa, 2013.

THUN, Harald; RADTKE, Edgar. Nuevos caminos de la geolinguística románica. Un balance. In: RADTKE, Edgar; THUN, Harald. Neue Wege der Romanischen Geolinguistik. Kiel: Westensee-Verlag, 1996. p. 25-49.

ZÁGARI, Mário et al. Esboço de um atlas linguístico de Minas Gerais. Rio de Janeiro: Fundação Casa de Rui Barbosa, 1977. v. 1. 